\title{
Surface Morphology, Roughness and Wettability of the Medical Grade 316L Stainless Steel Processed with Surface Mechanical Attrition Treatment and Electropolishing for the Preparation of Osteosynthesis Plate
}

\author{
Budi Arifvianto, ${ }^{*}$ Suyitno and Muslim Mahardika \\ Center for Innovation of Medical Equipments and Devices (CIMEDs), \\ Department of Mechanical and Industrial Engineering, \\ Faculty of Engineering, Universitas Gadjah Mada, \\ Jl. Grafika 2 Yogyakarta 55281, Indonesia \\ *Corresponding author: b.arifvianto@gmail.com
}

Published online: 25 November 2018

To cite this article: Arifvianto, B., Suyitno \& Mahardika, M. (2018). Surface morphology, roughness and wettability of the medical grade $316 \mathrm{~L}$ stainless steel processed with surface mechanical attrition treatment and electropolishing for the preparation of osteosynthesis plate. J. Phys. Sci., 29(3), 83-94, https://doi.org/10.21315/jps2018.29.3.7

To link to this article: https://doi.org/10.21315/jps2018.29.3.7

\begin{abstract}
In this research, medical grade 316L stainless steel plate was treated by using surface mechanical attrition treatment (SMAT) and electropolishing (EP) to achieve a hard and smooth surface, as required for osteosynthesis plates for bone fracture reconstruction. Surface morphology, roughness and wettability of the plate after a series of treatments by using the SMAT and EP were then characterised, and the results were compared with the surface properties of osteosynthesis plate reported in the literature. The result of this research showed that the SMAT could increase the hardness of the surface and subsurface layer of the plate but could not produce a smooth surface as required for an osteosynthesis plate. Meanwhile, such a smooth surface could be achieved after the EP. With this treatment, surface hydrophobicity of the stainless steel also slightly increased, but with no surface hardening effect such as shown by the SMAT. To deal with this conflicting situation, EP was applied after SMAT to produce stainless steel plate with a smooth and hard surface.
\end{abstract}

Keywords: Surface mechanical attrition treatment, electropolishing, surface characteristics, 316L stainless steel, osteosynthesis plate 


\section{INTRODUCTION}

In the last few decades, osteosynthesis plate has been considered as the standard medical device that can used to aid the healing and reconstruction of bone fracture. Once implanted together with a set of fixation screws, the plate provides stable fixation and longitudinal compression for the fractured bone, which are needed to promote healing and reconstruction process of the injured bone. ${ }^{1}$ Until now, medical grade 316L stainless steel has been chosen as the standard material for the osteosynthesis plate, owing to its biocompatibility and anti-corrosion properties..$^{1-3}$ However, failures of the osteosynthesis plate fabricated from this material had been reported in the open literature, mainly due to overloading and fatigue fracture.,4 Therefore, improvement of mechanical properties of osteosynthesis plate fabricated from the standard medical grade $316 \mathrm{~L}$ stainless steel remains necessary.

In earlier studies, it is reported that mechanical properties and fatigue resistance of the medical grade $316 \mathrm{~L}$ stainless steel could be increased by using surface mechanical attrition treatment (SMAT). ${ }^{5-7}$ With this treatment, surface hardness, tensile strength, fatigue resistance and wear resistance of metallic materials increased, owing to the formation of nanocrystallites at their surface and subsurface layer. ${ }^{5-10}$ On the basis of these studies, it is reported that the SMAT had recently been applied to increase fatigue resistance of osteosynthesis plate prepared from the medical grade $316 \mathrm{~L}$ stainless steel. ${ }^{11}$ However, on the other hand, it is also noted that the SMAT produced stainless steel plate with a considerably rough surface, i.e., with arithmetic medium value $\left(R_{a}\right)$ of $1.0 \mu \mathrm{m}$, as compared with the roughness of osteosynthesis plate reported in the literature, i.e., $R_{a}=0.59-0.88 \mu \mathrm{m} .{ }^{1,8,12}$

Surface roughness and wettability have so far been considered as critical parameters that could be used to evaluate the mechanical properties and biocompatibility of osteosynthesis plate. ${ }^{1}$ Corrosion and fatigue resistance of stainless steel would deteriorate due to irregularities of the surface. ${ }^{13-16}$ In addition, the risk of an implant with rough surface from being infected by microbial increased, owing to enlarged surface area of the implant for bacterial colonisation. ${ }^{17}$ It is also reported that bacterial adhesion to a surface depends on the implant surface wettability, where a sterile implant generally possesses a hydrophobic surface. ${ }^{17,18}$ Hence, a less-hydrophobic surface of the stainless steel treated with the SMAT should be avoided in the design of osteosynthesis plates. ${ }^{8}$

In this research, the use of SMAT and electropolishing (EP) in the preparation of osteosynthesis plate made from $316 \mathrm{~L}$ stainless steel was studied. Basically, the EP was used for a surface finishing of metallic parts with a complex shape. ${ }^{19,20}$ A preliminary study showed that the EP could lower the roughness of 316L 
stainless steel after the SMAT. ${ }^{21}$ However, further investigation related to the effects of such hybrid treatment on surface structure and wettability should be carried out to ensure that this treatment could meet the clinical requirements for the preparation of osteosynthesis plate. In this work, the influences of SMAT, EP and their combination on surface morphology, roughness, wettability and subsurface microhardness distribution of medical grade 316L stainless steel are discussed.

\section{EXPERIMENTAL}

In this research, medical grade $316 \mathrm{~L}$ stainless steel plates with chemical compositions (\%wt) of $0.03 \mathrm{C}, 16.69 \mathrm{Cr}, 10.57 \mathrm{Ni}, 2.39 \mathrm{Mo}, 1.74 \mathrm{Mn}, 0.67 \mathrm{Si}$, $0.34 \mathrm{Cu}$ and balanced $\mathrm{Fe}$ were prepared as the specimen with a dimension of $100 \mathrm{~mm} \times 50 \mathrm{~mm} \times 4 \mathrm{~mm}$. All the specimens were first cleaned by using $70 \%$ ethanol (PT Jayamas Medical Industri, Indonesia) prior to the treatments.

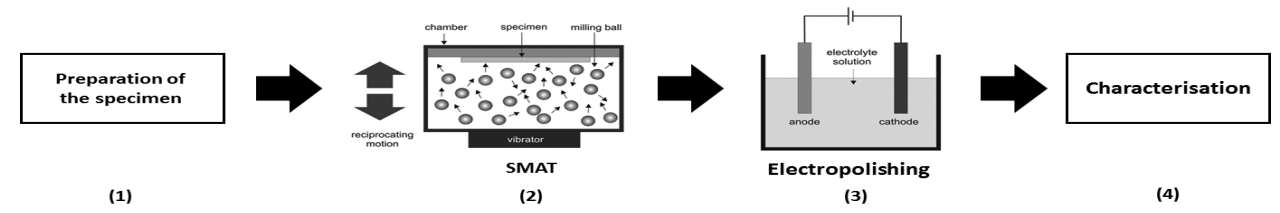

Figure 1: Schematic illustration of the experimental setup.

As illustrated schematically in Figure 1, the SMAT was carried out by vibrating a rigid chamber with 250 spherical milling balls having $4.76 \mathrm{~mm}$ in diameter inside. The specimen was placed at the upper side of the chamber. During the treatment, the specimen surface received multiple impacts of the milling balls. Meanwhile, as also schematically shown in Figure 1, EP was carried out by utilising a pair of cathode and anode that were both prepared from 316L stainless steel, immersed in an electrolyte solution with a separating gap of $35 \mathrm{~mm}$. In this case, the anode of this treatment was the specimen subjected to EP. An electric current and voltage of $36 \mathrm{~A}$ and $9.5 \mathrm{~V}$, respectively, were applied for 0-20 min during the treatment. The electrolyte solution was composed of $96 \% \mathrm{H}_{2} \mathrm{SO}_{4}$ and $85 \% \mathrm{H}_{3} \mathrm{PO}_{4}$ solutions, mixed together in a ratio of 1:1. In this research, both the as-received and the SMAT specimens were treated with EP.

Surface morphology of the specimen was examined by using scanning electron microscope (SEM; Quanta 250, Oxford Instrument, UK). Prior to the measurement, the specimen was first cleaned through sonication in $99 \%$ ethanol (Wako, Japan). Energy dispersive X-ray (EDX) spectroscopy analysis was also performed to characterise surface elements of the specimen. 
Surface roughness of both the as-received and treated specimens was measured using Surfcom 120A contact stylus profilometer (Advanced Metrology System, UK). The specimen was first cleaned with 70\% ethanol (PT Jayamas Medical Industri, Indonesia) prior to the measurement. With this measurement, the average of arithmetic medium values $\left(R_{a}\right)$ of the surface specimen was determined in triplicate.

Surface wettability of the specimen was evaluated by using sessile droplet contact angle test. Prior to the test, the specimen was also cleaned by using $70 \%$ ethanol, rinsed in distilled water, and dried at room temperature. A distilled water droplet was then injected through a syringe and deposited at five different locations on the surface of the specimen. A two-dimensional image of static water droplet on the surface of the specimen were then captured by using SX20IS digital camera (Canon, Japan). The contact angle of the water droplet deposited on the surface of the specimen was then determined through image analysis.

To confirm the surface hardening due to the SMAT, microhardness distribution across the specimen sectional area was characterised by using Vickers microhardness tester (Buehler, US). The specimen was first mounted in resin, ground and then polished mechanically prior to the testing. Vickers indentation test was carried out with an indentation load of $4.9 \mathrm{~N}$ for $15 \mathrm{~s}$.

\section{RESULTS AND DISCUSSION}

Figure 2 shows a series of SEM micrographs illustrating the changes in the surface morphology of the stainless steel after SMAT, EP and their combination. The surface of as-received specimen could be recognised from its irregular structure, consisting of protrusions and cracks spreading over the surface of stainless steel, such as seen in Figure 2(a). By using EP, such irregular structure could be eliminated and a smooth surface could then be achieved, as indicated in Figure 2(b). Meanwhile, the multiple impacts of milling balls during the SMAT deformed protrusions plastically and resulted in a flat surface, though some pits could still be observed, indicating unimpacted region at the specimen surface, as demonstrated in Figure 2(c). Finally, in Figure 2(d), stainless steel surface with a morphology similar to that in Figure 2(b) could be produced, after a treatment with SMAT and EP. 


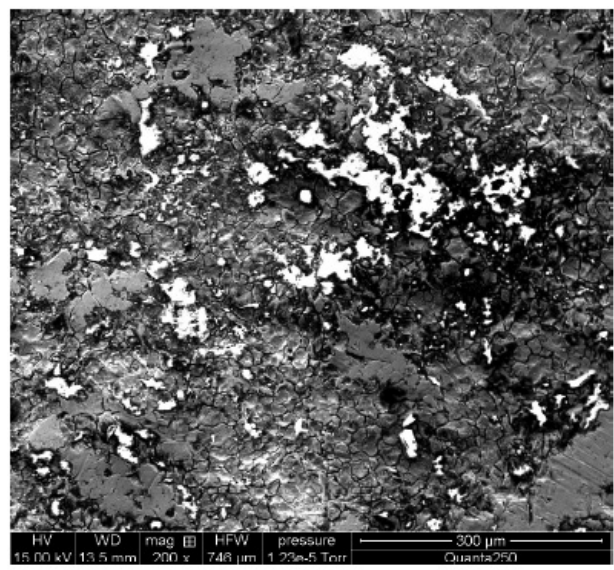

(a) As-received

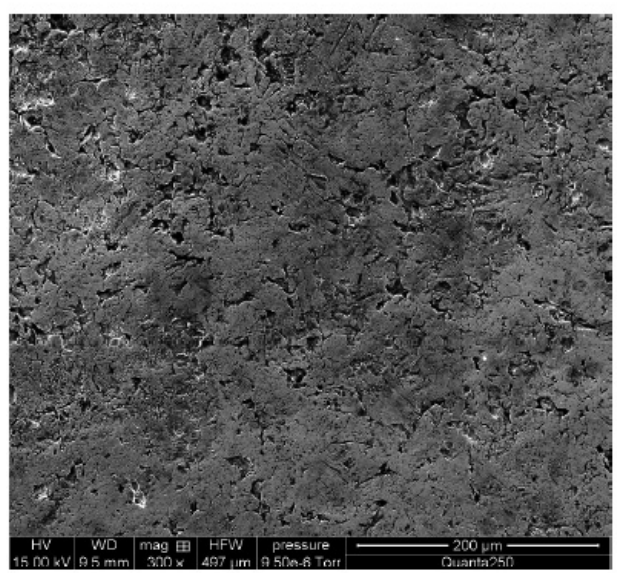

(c) After SMAT

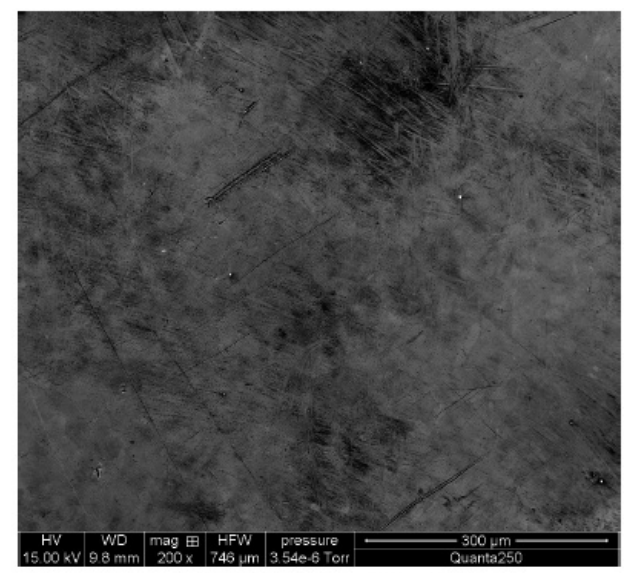

(b) After electropolishing EP

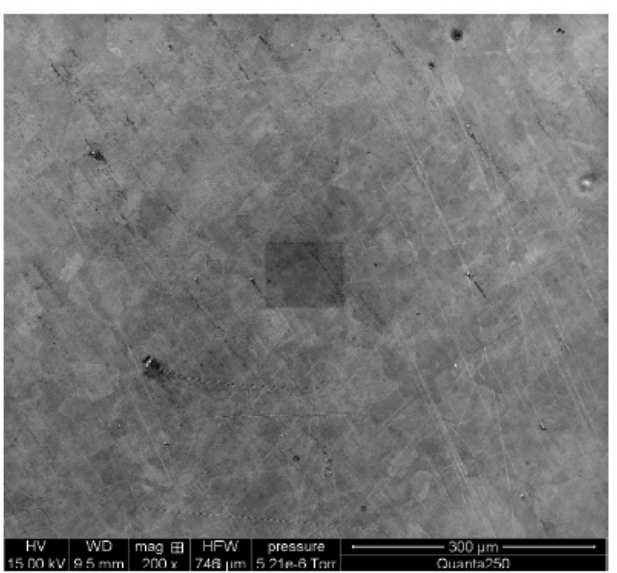

(d) After SMAT and EP

Figure 2: SEM micrographs of 316L stainless steel surface: (a) as-received, (b) after EP, (c) after the SMAT and (d) after the combination of the SMAT and EP.

The results of roughness measurement of both the as-received and the treated surface of the stainless steel are shown in Figure 3. As seen in this figure, the $R_{a}$ of the steel surface decreased from $3.98 \mu \mathrm{m}$ to $0.99 \mu \mathrm{m}$ due to the SMAT. Meanwhile, the EP produced a smoother surface than the SMAT, i.e., with $R_{a}=0.65 \mu \mathrm{m}$. The EP for $20 \mathrm{~min}$ for the SMAT specimen resulted in a steel surface with $R_{a}=0.15 \mu \mathrm{m}$. 


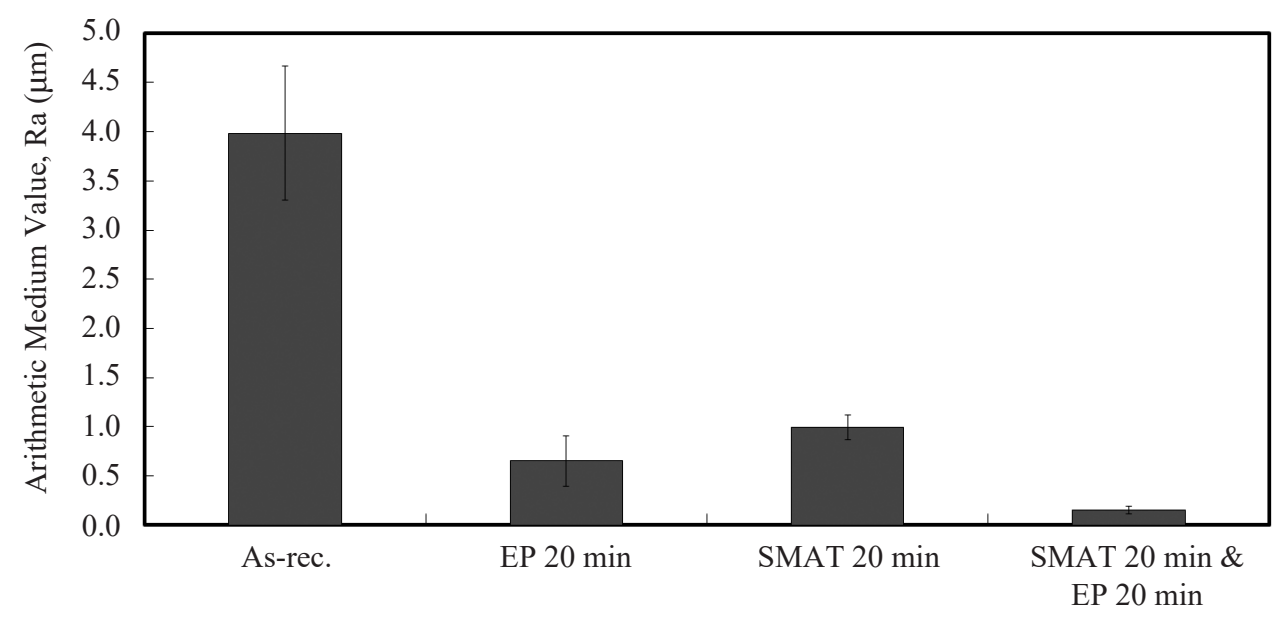

Figure 3: Surface roughness of the specimen prior to and after the treatments.

The formation of a rough surface at the specimen with the SMAT corresponds to the formation of new peaks and valleys resulting from the impacts of milling balls. ${ }^{8}$ However, the roughness of an initially rough surface decreased after the SMAT, as the existing peaks, i.e., protrusions, on such surface were deformed by the multiple impacts of milling balls. In earlier study, it is also reported that the SMAT produced a surface with saturated roughness of $R_{a} \approx 1.0 \mu \mathrm{m}$, which was higher than the $R_{a}$ values of osteosynthesis plate, i.e., $R_{a}=0.59-0.88 \mu \mathrm{m} .{ }^{1,8,12}$

The use of EP to decrease the roughness of $316 \mathrm{~L}$ stainless steel is confirmed in this study. With this treatment, the irregular surface structure of as-received specimen disappeared due to electrochemical dissolution in EP process. ${ }^{19,20}$ In this case, it is also noted that surface roughness of the steel decreased with the increasing duration of EP. A similar finding is reported in the works of Lee and Lai and also Lee. ${ }^{19,20}$ Changes in the surface roughness resulting from EP also depend on initial roughness of the specimen. As demonstrated in this research, the application of EP for certain duration of treatment after the SMAT resulted in a specimen with smoother surface, compared to the as-received or even the EP specimens. The work of Lee and Lai also showed that the EP produced a smoother surface from an initially less rough specimen. ${ }^{19}$ In this case, to achieve certain roughness, treatment with EP on an initially rough surface took longer than that on a smoother one. Pre-treatment, for instance mechanical polishing, was required to improve surface finish of a material by using EP. ${ }^{19}$ In this experiment, the ability of the SMAT to decrease the roughness led to the use of this treatment prior to EP to improve surface finish of $316 \mathrm{~L}$ stainless steel. 
As indicated in a previous study, a rough surface obtained from the SMAT might be inappropriate for the design of osteosynthesis plate. ${ }^{1}$ With such a rough surface, corrosion resistance and fatigue resistance of a metallic material might reduce. ${ }^{13-16}$ Meanwhile, the susceptibility of biomaterials or implants to bacterial adhesion generally increased with the increasing surface roughness of the materials. ${ }^{17}$ In this research, EP obviously altered the rough and irregularly-structured surface of the stainless steel (as processed with the SMAT) to a dense surface with a freedefect and smooth appearance. Based on the measured surface roughness, it is also noted that a specimen surface with $R_{a}$ of $0.1 \mu \mathrm{m}$ could be obtained by using the EP for certain duration of treatment after the SMAT. Compared with the results reported in a previous study, the $R_{a}$ value of $316 \mathrm{~L}$ stainless steel processed with the SMAT and EP was lower than that of the standard osteosynthesis plate, i.e., $R_{a}=0.59-0.88 \mu \mathrm{m}$. $^{1}$

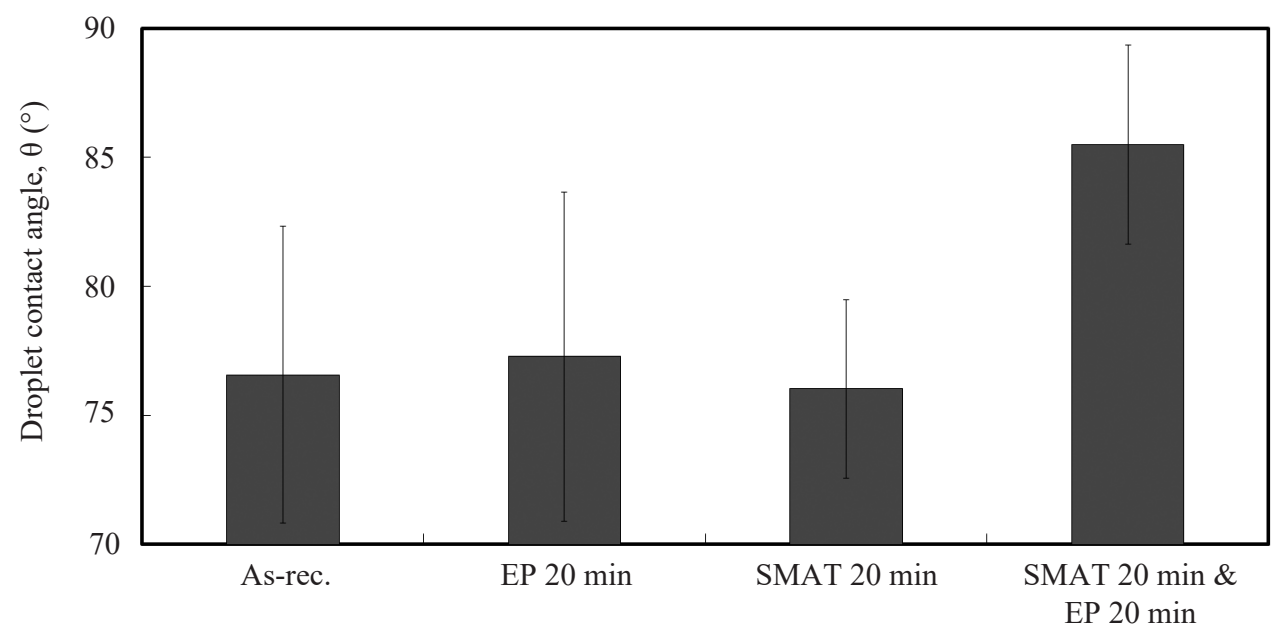

Figure 4: Surface wettability of the specimen prior to and after the treatments.

The effect of all the treatments performed in this research on static droplet contact angle deposited on the specimen surface was indicated in Figure 4. Apparently, both SMAT and EP did not alter the droplet contact angle. However, the EP treatment for 20 min after the SMAT resulted in the largest contact angle of the droplet deposited on the surface of the specimen. On the basis of this study, it is apparent that the SMAT did not influence the droplet contact angle, though it was able to decrease the roughness of the as-received specimen. As noted earlier, the SMAT has only a minor effect on surface wettability of 316L stainless steel. ${ }^{8}$ Meanwhile, as demonstrated in this research, the application of EP decreased the roughness, but slightly increased droplet contact angle on the surface of 
316L stainless steel specimen. The EP for certain duration of treatment after the SMAT could produce a larger droplet contact angle as compared to that of the EP surface. This phenomenon might be caused by the presence of smooth surface and nanocrystallites, produced by the combination of the SMAT and EP. However, further studies are needed to confirm this finding.

Surface wettability is a critically important aspect that should be considered in attempt to prevent bacterial contamination to biomedical implants. Hydrophilic bacteria could preferably adhere on a hydrophilic surface, whereas the hydrophobic ones tend to contaminate implants with hydrophobic surface. ${ }^{17}$ As demonstrated in this research, the droplet contact angle on the specimen treated with the combination of SMAT and EP was $\theta=85.5^{\circ}$; which was close to the contact angle of droplet deposited on the surface of osteosynthesis plate, i.e., $\theta=87^{\circ}$ and mechanically polished $316 \mathrm{~L}$ stainless steel with $R_{a}=0.04 \mu \mathrm{m}$, i.e., $\theta=88.6^{\circ} .1,8$ According to the previous studies, this finding might indicate a less hydrophilic property of stainless steel surface that had been treated with the combination of SMAT and EP, as compared to the as-received specimen and the specimens with the SMAT or EP. ${ }^{22,23}$ These properties might be beneficial since the adhesion of hydrophilic and hydrophobic bacteria on this surface might not be as powerful as the adhesion on a highly hydrophilic and hydrophobic surface.

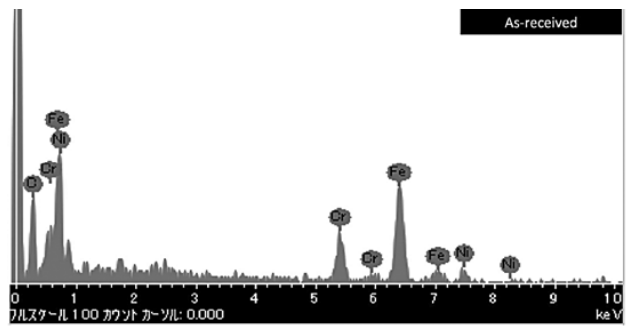

(a)

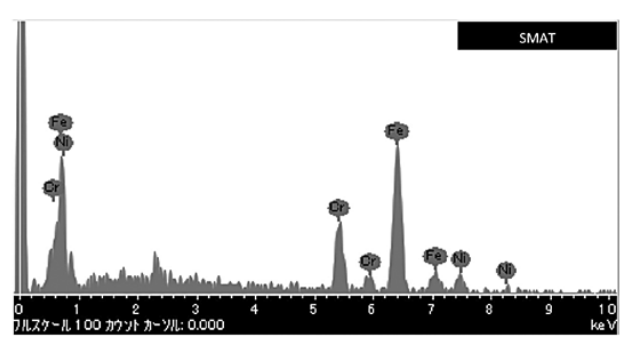

(c)

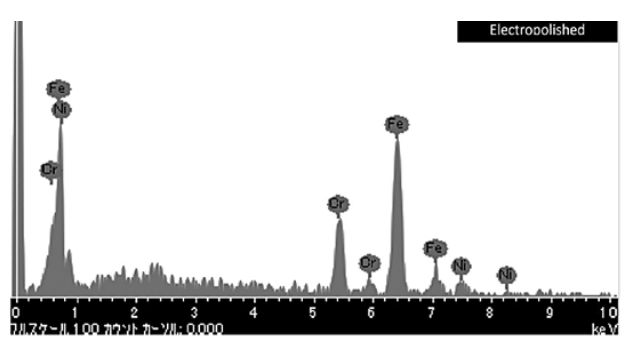

(b)

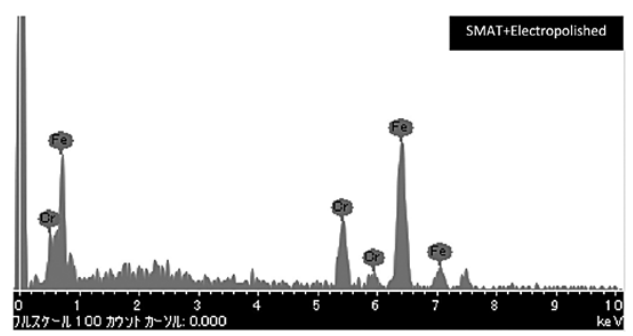

(d)

Figure 5: EDX spectra of (a) as-received specimen and specimens after (b) EP, (c) SMAT and (d) combined SMAT + EP. 
Figure 5 shows elemental compositions of the surface of the specimen, as revealed from the EDX spectroscopic analysis. In general, all the treated specimens indicated the presence of primary elements of stainless steel such as $\mathrm{Fe}, \mathrm{Cr}$ and Ni. By using EP for 20 min after the SMAT, the $\mathrm{C}$ and Ni elements at the surface of the specimen could be eliminated, as indicated in Figure 5(d). This finding obviously indicated that the presence of undesired elements for biomedical implant applications, such as carbon (C) and nickel (Ni), at the surface of as-received specimen. In this research, it is shown that both $\mathrm{C}$ and $\mathrm{Ni}$ were no longer seen after surface dissolution and wear that happened during the SMAT and EP.

In earlier studies, the application of SMAT to enhance mechanical properties of $316 \mathrm{~L}$ stainless steel has been reported in literatures ${ }^{5-7} \mathrm{In}$ this research, the increased micorhardness from $H_{v}=1.6 \mathrm{GPa}$ to $2.9 \mathrm{GPa}$ at a depth of $100 \mu \mathrm{m}$ from the surface of the $316 \mathrm{~L}$ stainless steel due to the SMAT is confirmed by the results of the previous works. ${ }^{5,7}, 8$ As also noted in those works, the multiple impacts of milling balls during the SMAT were able to induce grain refinement at the surface and subsurface layer of the stainless steel, resulting in a material with a hard surface layer and improved mechanical properties. ${ }^{5-8}$

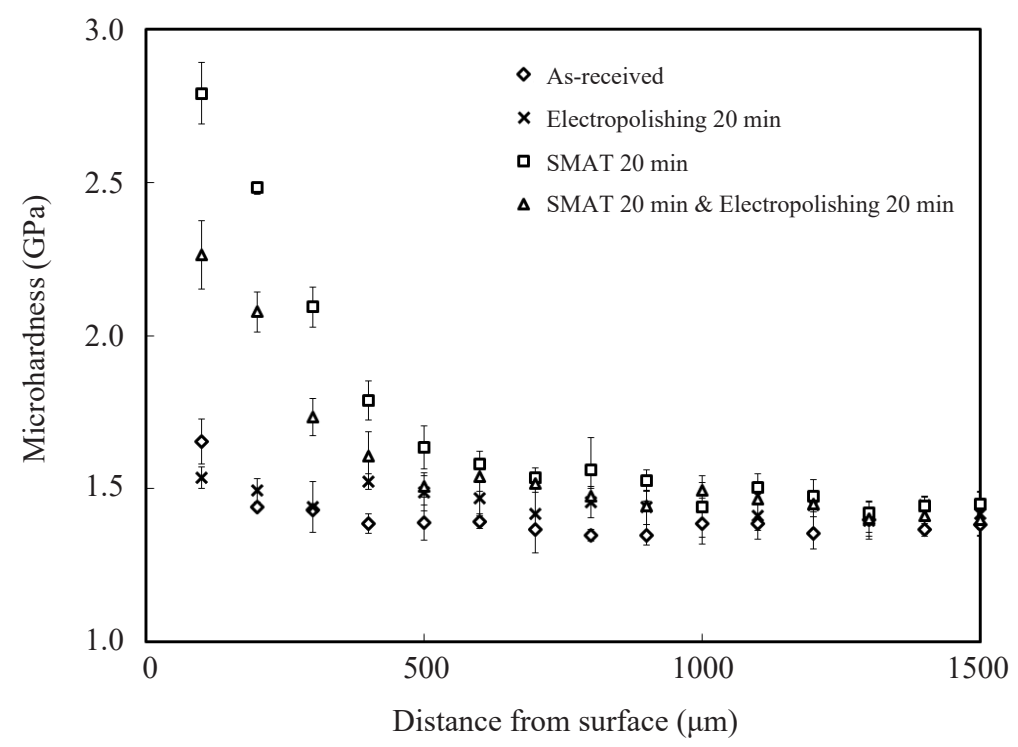

Figure 6: Subsurface microhardness distribution over the specimen cross-sectional area.

The subsurface microhardness distribution over the specimen cross-sectional area is presented in Figure 6. SMAT increased microhardness of the specimen subsurface, i.e., from $H_{v}=1.6 \mathrm{GPa}$ to $2.9 \mathrm{GPa}$, as measured at $100 \mu \mathrm{m}$ deep from the surface. As shown in Figure 6, a hard surface layer with $800 \mu \mathrm{m}$ thick 
could be formed after 20 min of the SMAT. Meanwhile, EP did not influence the microhardness of the as-received specimen, but it reduced the microhardness of the SMAT-processed specimen, as indicated by the decreased $H_{v}$ from $2.9 \mathrm{GPa}$ to 2.2 $\mathrm{GPa}$, as measured at $100 \mu \mathrm{m}$ deep from the surface. Since the EP dissolved the surface layer of the specimen, the thickness of the hard surface layer formed by the SMAT decreased. Nevertheless, the surface of the specimen after the combined treatment of SMAT and EP remained harder than both the as-received and EP specimens. A longer duration of EP might result in total elimination of the hard surface layer that had been produced by the SMAT. Therefore, duration of EP should be applied appropriately. In this research, the combined treatment, i.e., 20 min of SMAT followed by $20 \mathrm{~min}$ of EP, was considered promising to generate stainless steel with a hard but smooth surface; demonstrating the advantage of this particular treatment for post-processing technique to produce osteosynthesis plate with improved mechanical properties and biocompatibility.

\section{CONCLUSION}

In this research, the effects of SMAT combined with EP on surface morphology, roughness and wettability of $316 \mathrm{~L}$ stainless steel were studied. Based on the results of this research, it is concluded that the EP for 20 min after 20 min SMAT could generate $316 \mathrm{~L}$ stainless steel with a hard, smooth and less hydrophilic surface, which are relevant and required in the design of osteosynthesis plate.

\section{ACKNOWLEDGEMENTS}

This work is financially funded by Department of Mechanical and Industrial Engineering, Faculty of Engineering, Universitas Gadjah Mada, Indonesia with grant no. 1437/H1.17/TMI/PL/2011.

\section{REFERENCES}

1. Dewo, P. (2010). Evaluation and redesign of an osteosynthesis plate, produced in Indonesia. PhD diss., University of Groningen, Netherlands.

2. Triantafylllidis, G. K., Kazantzis, A. V. \& Karageorgiou, K. T. (2007). Premature fracture of a stainless steel $316 \mathrm{~L}$ orthopaedic plate implant by alternative episodes of fatigue and cleavage decoherence. Eng. Fail. Anal., 14, 1346-1350, https://doi.org/10.1016/j.engfailanal.2006.11.010. 
3. Holzach, P. \& Matter, P. (1979). The comparison of steel and titanium dynamic compression plates used for internal fixation of 256 fractures of the tibia. Injury, 10, 120-123, https://doi.org/10.1016/S0020-1383(79)800728.

4. Brunner, H. \& Simpson, J. P. (1980). Fatigue fracture of bone plates. Injury, 11, 203-207, https://doi.org/10.1016/S0020-1383(80)80044-1.

5. Roland, T. et al. (2007). Enhanced mechanical behavior of a nanocrystallised stainless steel and its thermal stability. Mater. Sci. Eng. A, 445-446, 281288, https://doi.org/10.1016/j.msea.2006.09.041.

6. Chen, X. et al. (2005). Tensile properties of a nanocrystalline $316 \mathrm{~L}$ austenitic stainless steel. Scrip. Mater., 52, 1039-1044, https://doi.org/10.1016/j. scriptamat.2005.01.023.

7. Roland, T. et al. (2006). Fatigue life improvement through surface nanostructuring of stainless steel by means of surface mechanical attrition treatment. Scrip. Mater., 54, 1949-1954, https://doi.org/10.1016/j. scriptamat.2006.01.049.

8. Arifvianto, B. et al. (2011). Effect of surface mechanical attrition treatment (SMAT) on microhardness, surface roughness and wettability of AISI 316L. Mater. Chem. Phys., 125, 418-426, https://doi.org/10.1016/j. matchemphys.2010.10.038.

9. Wang, Z. B., Lu, J. \& Lu, K. (2006). Wear and corrosion properties of a low carbon steel processed by means of SMAT followed by lower temperature chromizing treatment. Surf. Coat. Technol., 201, 2796-2801, https://doi. org/10.1016/j.surfcoat.2006.05.019.

10. Zhang, Y. S. et al. (2006) Friction and wear behaviors of nanocrystalline surface layer of pure copper. Wear, 260, 942-948, https://doi.org/10.1016/j. wear.2005.06.010.

11. Dewo, P. et al. (2015). Redesign of Indonesian-made osteosynthesis plates to enhance their mechanical behaviour. J. Mech. Behav. Biomed. Mater., 42, 274-281, https://doi.org/10.1016/j.jmbbm.2014.11.025.

12. Arifvianto, B., Suyitno \& Mahardika, M. (2012). Effects of surface mechanical attrition treatment (SMAT) on a rough surface of AISI 316L stainless steel. Appl. Surf. Sci., 258, 4538-4543, https://doi.org/10.1016/j. apsusc.2012.01.021.

13. Lee, H. et al. (2009). Influence of peening on the corrosion properties of AISI 304 stainless steel. Corr. Sci., 51, 2826-2830, https://doi.org/10.1016/j. corsci.2009.08.008.

14. Hao, Y. et al. (2009). Effect of surface mechanical attrition treatment on corrosion behavior of 316 stainless steel. J. Iron Steel Res., 16, 68-72, https://doi.org/10.1016/S1006-706X(09)60030-3. 
15. Ryu, J. H. \& Nam, S. W. (1989). Effect of surface roughness on lowcycle fatigue life of Cr-Mo-V steel at $550^{\circ} \mathrm{C}$. Int. J. Fatigue, 11, 433-436, https://doi.org/10.1016/0142-1123(89)90183-7.

16. Lee, J. M. \& Nam, S. W. (1990). Effect of crack initiation mode on low cycle fatigue life of type 304 stainless steel with surface roughness. Mater. Lett., 10, 223-230, https://doi.org/10.1016/0167-577X(90)90022-E.

17. An, Y. H. \& Friedmann, R. J. (1998). Concise review of mechanisms of bacterial adhesion to biomaterial surfaces. J. Biomed. Mater. Res., 43, 338-348, https://doi.org/10.1002/(SICI)1097-4636(199823)43:3<338::AIDJBM16>3.0.CO;2-B.

18. Furstner, R. et al. (2005). Wetting and self-cleaning properties of artificial superhydrophobic surfaces. Langmuir, 21, 956-961, https://doi. org/10.1021/la0401011.

19. Lee, S. J. \& Lai, J. J. (2003). The effects of electropolishing (EP) process parameters on corrosion resistance of $316 \mathrm{~L}$ stainless steel. J. Mater. Process. Technol., 140, 206-210, https://doi.org/10.1016/S0924-0136(03) 00785-4.

20. Lee, E. S. (2000). Machining characteristics of the electropolishing of stainless steel (STS316L). Int. J. Adv. Manuf. Technol., 16, 591-599, https://doi.org/10.1007/s001700070049.

21. Arifvianto, B., Suyitno \& Mahardika, M. (2011). Hybrid surface treatment for improving mechanical and surface properties of AISI $316 \mathrm{~L}$ stainless steel. Paper presented at the 2nd International Conference on Instrumentation, Communication, Information Technology and Biomedical Engineering, Institut Teknologi Bandung (ITB), Bandung, 8-9 November, 315-318.

22. Bico, J., Tordeux, C. \& Quere, D. (2001). Rough wetting. Europhys. Lett., $55,214-220$.

23. Uelzen T. \& Muller, J. (2003). Wettability enhancement by rough surfaces generated by thin film technology. Thin Solid Films, 434, 311-315, https://doi.org/10.1016/S0040-6090(03)00484-X. 